\title{
Design and Computational Fluid Dynamic Simulation Study of High Efficiency Cross Flow Hydro-power Turbine
}

\author{
Gutu Birhanu Oliy ${ }^{1}$, Auch Venkata Ramayya ${ }^{2}$ \\ ${ }^{1}$ Rural Energy Engineering Research Team Bako Agricultural Engineering Resarch Center, Oromia Agricultural Research Institute, Oromia, \\ Ethiopia \\ ${ }^{2}$ School of Mechanical Engineering, Institute of Technology, Jimma University, Oromia, Ethiopia
}

Email address:

gtbr2006@gmail.com (G. B. Oliy), venkata9999@yahoo.com (A. V. Ramayya)

To cite this article:

Gutu Birhanu Oliy, Auch Venkata Ramayya. Design and Computational Fluid Dynamic Simulation Study of High Efficiency Cross Flow Hydro-power Turbine. International Journal of Science, Technology and Society. Vol. 5, No. 4, 2017, pp. 120-125.

doi: $10.11648 /$ j.ijsts. 20170504.20

Received: May 26, 2017; Accepted: June 12, 2017; Published: July 18, 2017

\begin{abstract}
Cross-flow hydraulic turbine becomes viable in low head and small water flow rate. Because of its simple in structure and ease of manufacturing, it is familiar in scheme of small hydro-power in the site of the power plant. In order to obtain a cross-flow turbine with maximum efficiency, appropriate turbine design must be performed. Therefore here proper turbine design was done employing the all turbine parameters and computational fluid dynamic simulation was carried out as important tool for performance study of the turbine. The required turbine model was designed and computational fluid dynamics simulations was performed by using the commercial software ANSYS CFX v.12. After the high efficiency turbine was designed, computational fluid dynamics was conducted in order to validate the obtained solution. With attack angle of $18^{0}$, maximum efficiency was found to be $82.52 \%$ constant for different values of head and water flow rate. Where as in CFD simulation case, maximum efficiency became $79 \%$ with fully opened guide vane. Guide vane was set at position where the water is discharge through the runner fully. In this paper all design parameters of cross-flow turbine were calculated at maximum efficiency and simulation was done by opening turbine gate value at different stages.
\end{abstract}

Keywords: Cross-Flow Turbine, Design Parameters, Efficiency, CFD

\section{Introduction}

Several small hydro-power schemes have been proposed and successfully employed, which include radial, axial, and propeller type turbines. Nowadays, the cross-flow hydraulic turbine is gaining popularity in low head and small water flow rate establishments, due to its simple structure and ease of manufacturing in the site of the power plant.

Cross-flow turbine is composed of two major parts, the runner and the nozzle. The runner is a circular rotor with two side walls to which the blades are fixed along the periphery of the turbine and blades are circular with specific radius of curvature. The nozzle directs the water flow into the runner at a certain attack angle. The water flow comes through an inlet pipe, and then it is regulated by guide vanes and finally enters the runner of the turbine. After passing through, the water leaves on the opposite side of the runner, providing so additional efficiency.

The efficiency of the cross-flow turbine is dependent on several design parameters. These include runner diameter, runner length, runner speed, turbine power, water jet thickness, blade spacing, number of blades, radius of blade curvature, attack angle and the blade and exit angles [1].

Since the beginning and establishment of cross flow turbine, considerable development has been made in its design through experimental studies and researches. Khosrowpanah [2] conducted a study on effect of number of blades, runner diameter and nozzle entry arc under head variations on the performance of cross flow turbines. Under this experiment, water is admitted vertically through a nozzle 6 inches wide with nozzle entry arc angle of 58, 78 and 90. He concluded that maximum efficiency of the cross flow turbine increases with an increase in the nozzle entry arc from 58 to 90 and decreases slightly with a decrease in runner diameter at constant runner width. 
Nakase [3] conducted experiments to study the effect of nozzle shape on the performance of cross-flow turbines where outer diameter of the runner is $315 \mathrm{~mm}$ and the runner has 26 blades, with blade inlet and outlet angles of 30 and 90 . He concluded that there are crossed and uncrossed flow types of flow in the cross-flow turbine. The crossed flow constitutes a major portion of the flow which gives rise to flow contraction causing the flow to accelerate from the first stage to the second.

Akerkar [4] conducted experiment on laboratory studies on the efficiency of cross flow turbine. The study involved evaluating the effect of factors such as angle of attack, nozzle entry arc and nozzle entry configuration on the turbine efficiency and three runners were constructed with angles of attack 16, 20 and 24. He concluded that the flow pattern inside the cross flow turbine runner is concave when viewed from the shaft center. The jet angle at the first stage exit is greater for the vertical position of the nozzle than either the slant or the horizontal positions. The horizontal position of the nozzle was also concluded to be the least efficient.

Fiuzat and Akerkar [5] reported that the flow pattern inside the cross flow turbine runner is concave when viewed from the shaft center. The maximum efficiency attained without the interior guide tube was $89 \%$ for 90 degrees and with an angle of attack of 24 degrees. They also reported that efficiency increased with an increase in the angle of attack from 16 to 24, thus contradicting Banki's theory of cross flow turbines.

Chappell [6] indicated that cross flow turbines manufactured out of standard Plexiglas plastic pipes or sheets can substantially reduce the cost of materials, manufacturing and repairs.

Simpson [7] mentions that cross flow turbine can handle a wide range of flow rates and head values and is simple in construction and capable of self- cleaning. He concludes that these reasons make the cross flow turbine an excellent turbine for run-of-stream hydro power plants with head values of more than $5 \mathrm{ft}$.

Olgun $[8,9]$ in his reported works concluded that crossflow turbines can be operated efficiently in a wider range of gate openings than most turbines. Maximum efficiency occurs at a constant speed for all gate openings at constant head. Meanwhile, maximum efficiency change with increasing the head at constant gate openings and the runner with diameter ratio 0.67 is more efficient than the runners with diameter ratios of $0.54,0.58 \& 0.75$.

Durgin and Fay [10] constructed a cross-flow turbine in a configuration to allow extraction of the inter-stage cross flow and observation of the runner's internal flow patterns. The maximum efficiency attained was $61 \%$. The existing theory predicted a maximum efficiency of $87 \%$ while the modified theory predicted an efficiency of $66 \%$ indicating that entrained flow must be accounted for in predictive techniques.

Aziz and Desai [11] experimental study reveals that an increase in the diameter ratio produced an increase in the predicted maximum efficiency of the turbine under automatic speed control. They also concluded that somewhere in the vicinity of the diameter ratio of 0.68 , the cross-flow is maximum and results in maximum efficiency due to second stage contribution.

Thapar and Albertson [12] found that cross flow turbines are free from cavitation but are susceptible to wear when excessive silt and sand particles are present in the water. They also state that general maintenance is less complex than for other types of turbines as the runners are self-cleaning.

Since the CFD analysis of the flow is computationally quite difficult and cost, number of research works on this subject is quite low. However, there was few CFD simulation work has been done so far for cross flow hydraulic turbine. Thus, it was planned to design turbine and then carried out CFD simulation for validation purpose.

\section{Materials and Methods}

Conceptual Design of the turbine can be accomplished with design procedure of the cross-flow turbine as follow

\subsection{Preparing the Site Data}

This involves the calculations and measuring the net head of the hydro-power plant and its water flow rate.

i. Net head $\left(\mathrm{H}_{\mathrm{n}}\right)$ :

$$
H_{n}=\frac{H_{g}}{H_{t l}}(m)
$$

Where $\mathrm{H}_{\mathrm{g}}=$ the gross head which was the vertical distance between water surface level at the intake and at the turbine.

$\mathrm{H}_{\mathrm{tl}}=$ total head losses due to the open channel, trash rack, intake, penstock and gate or value.

ii. Water flow rate $(\mathrm{Q})$ :

The water flow rate can be calculated by measuring river or stream flow velocity $\left(V_{r}\right)$ and river cross-sectional area $\left(A_{r}\right)$, then:

$$
Q=V_{r} * A_{r}\left(m^{3} s^{-1}\right)
$$

\subsection{Turbine Power (Pt)}

The electrical power of the turbine in Watt can be calculated as

$$
p_{t}=\rho * g * H_{n} * Q * \eta_{t}(\mathrm{Watt})
$$

\subsection{Calculation of Turbine Efficiency ( $\eta t)$}

The maximum turbine efficiency can be calculated as:

$$
\eta_{t}=\frac{1}{2} * c^{2} *(1+\psi) * \cos ^{2}(\alpha)
$$

From equation (4) above, it's clear that the attack angle $(\alpha)$ should be kept as small as possible for maximum turbine efficiency.

\subsection{Turbine Speed (N)}

The correlation between specific speed $(N s)$ and net head is given for the cross-flow turbine as: 


$$
N_{s}=513.25 / H_{n}^{0.505}
$$

Also the specific speed in terms of turbine power in $K w$, turbine speed in (r. p.m.) and net head in $(m)$ is given as:

$$
N_{s}=N * \sqrt{P_{t}} / H_{n}^{5 / 4}
$$

From equations (5) and (6) above, the turbine speed can be:

$$
N=513.25 * H_{n}^{0.745} / \sqrt{P_{t}}(\text { r.p.m })
$$

\subsection{Runner Outer Diameter (Do) and Inner Diameter of the Runner (Di)}

At maximum efficiency, the tangential velocity of the runner outer periphery is given as:

$$
V_{t r}=\frac{1}{2} * C * \sqrt{2 * g * H_{n}} * \cos (\alpha)
$$

Also

$$
V_{t r}=w * \frac{D_{o}}{2}=\frac{2 \pi N D_{o}}{120}
$$

From equations (8) and (9) the runner outer diameter can be calculated as:

$$
D_{0}=40 * \sqrt{H_{n}} / N(m)
$$

Runner inner diameter can be calculated as follow:

$$
D_{i}=D_{o}-2 * a
$$

\subsection{Blade Spacing $\left(t_{b}\right)$}

The thickness of jet entrance $\left(t_{e}\right)$ measured at right angles to the tangential velocity of runner is given as:

$$
t_{e}=K * D_{o}(\mathrm{~m})
$$

Where $\mathrm{K}=$ constant $=0.087$

The tangential spacing $\left(\mathrm{t}_{\mathrm{b}}\right)$ is given as:

$$
t_{b}=t_{e} / \sin \left(\beta_{1}\right)=K * D_{0} / \sin \left(\beta_{1}\right)
$$

Where $\beta_{1}=$ blade inlet angle $=30^{\circ}$ when $\alpha=16^{0}$. Then

$$
t_{b}=0.174 * D_{o}
$$

\subsection{Radial Rim Width (a)}

It is the difference between the outer radius $\left(r_{o}\right)$ and inner radius $\left(r_{i}\right)$ of the turbine runner, and it is also equal to the blade spacing and can be given as:

$$
a=0.174 * D_{o}(\mathrm{~m})
$$

\subsection{Runner Blade Number (n) and Water Jet Thickness $\left(t_{j}\right)$}

The number of the runner blades can be determined as:

$$
n=\pi * D_{o} / t_{b}
$$

It is also defined as nozzle width and can be calculated as [2]:

$$
t_{j}=0.233 * Q /\left(L * \sqrt{\left.H_{n}\right)}\right.
$$

\subsection{Calculation of Runner Length (L)}

The runner length in $(m)$ can be calculated as: From reference:

$$
L * D_{o}=210 * Q / \sqrt{H_{n}}
$$

By transforming the British units of equation (17) above into metric units, it can be obtained as:

$$
L * D_{o}=0.81 * Q / \sqrt{H_{n}}
$$

Substitute equation (10) into (18) to obtain:

$$
L=Q * N / 50 * H_{n}(\mathrm{~m})
$$

Substitute equation (19) into (16) to obtain:

$$
t_{j}=117 * \sqrt{H_{n}} / N
$$

Also substitute equation (10) into (20) to obtain the jet thickness at maximum efficiency as:

$$
t_{j}=0.29 * D_{o}(\mathrm{~m})
$$

\section{Results and Discussion}

\subsection{Numerical Study}

Computational fluid dynamic study of the system starts with building desired geometry and mesh for modeling the domain. Meshing is the discretization of the domain into small volumes where the equations are solved by the help of iterative methods. Modeling starts with defining the boundary and initial conditions for the domain and leads to modeling the entire system domain. Finally, it is followed by the analysis of the results.

All the simulations were carried out at the design conditions of net head and discharge with constant runner speed. 3-Dimensional viscous steady of computational fluid dynamics simulations are performed by using the commercial software ANSYS CFX Version 12.1. As turbulence model, $\mathrm{k}-\varepsilon$ turbulence model closure with scalable wall functions is 
used. This near-wall treatment can be applied on arbitrarily fine grids and allows to perform a consistent grid refinement independent of the Reynolds number of the application. More details can be found in [13].

\subsection{Geometry}

Cross flow turbine and its casing are built in SOLID WORK workbench and imported to ANSYS workbench for analysis. The geometry was drawn in different views to easily be understood and simplified for visional investigation.

Guide vane was designed for inclination of zero angles to horizontal line and was adjusted for different flow conditions. But in this analysis, only fully discharge parameter is considered due to complexity. To increase negative pressure for a flow exit to turbine, draft tube was employed right to the case of the turbine. Figure 1 below shows some of important components of the cross flow turbine.

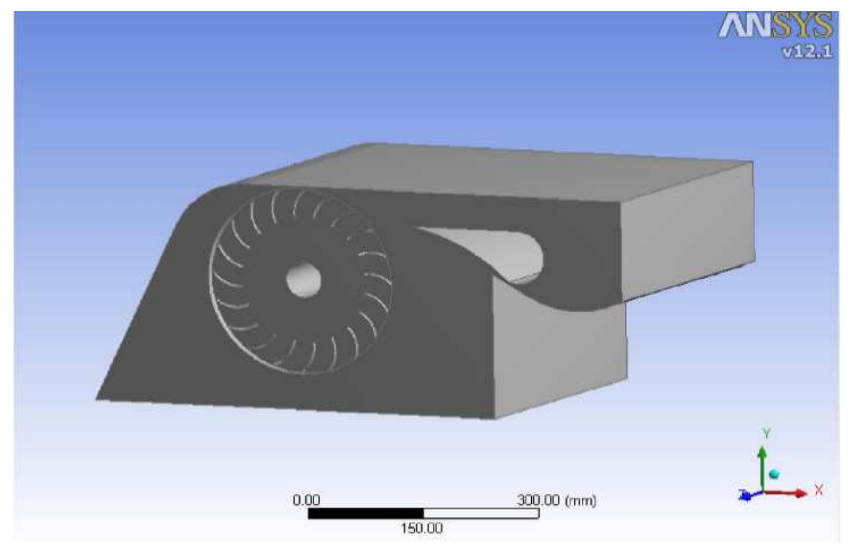

Figure 1. Simplified geometry of Cross flow turbine.

Table 1. Total dimension of cross flow hydro turbine.

\begin{tabular}{llll}
\hline No & Description & Unit & Value \\
\hline 1 & Overall Dimension & $\mathrm{cm}$ & $40 * 40 * 2$ \\
2 & Turbine & $\mathrm{cm}$ & $26.22 * 38.2$ \\
3 & Number of blades & number & 20 \\
4 & Disk size & $\mathrm{cm}$ & $26.22 * 5 * 3$ \\
5 & Guide Vane & $\mathrm{cm}$ & $39.5 * 19$ \\
\hline
\end{tabular}

\subsection{Geometry Meshing}

Initially a relatively coarser mesh is generated with 50,000 cells. This mesh contains mixed cells (Tetra and Hexahedral cells) having both triangular and quadrilateral faces at the boundaries. Care is taken to use structured cells (Hexahedral) as much as possible, for this reason the geometry is divided into several parts for using automatic methods available in the ANSYS meshing client. It is meant to reduce numerical diffusion as much as possible by structuring the mesh in a well manner, particularly near the wall region.

The accuracy of numerical results in CFD modelling was mesh dependent: the finer mesh generally provides better results at the increased computational time [14]. Therefore the size of the mesh in the domain should be gradually increased to such level that the further raise in the number of control volumes does not result in considerable changes in theoretical results produced.

Later on, for the mesh independent model, a fine mesh is generated with better cells. For this fine mesh, the edges and regions of high velocity and pressure gradients are finely meshed.

\subsection{Boundary Condition}

Boundary conditions are used according to the need of the model. The nozzle turbine is considered as linear inlet velocity and ambient temperature are used similar to the experimental conditions. At exit of the turbine, pressure outlet is preferred in order to have a comparison.

Turbine is considered as moving solid part at 500rpm and the outer case is imitated as fluid flow over the solid part. Guide vane was cut off fluid part. The walls are separately specified with respective boundary conditions. 'No slip' condition is considered for each wall.

Table 2. Boundary Condition.

\begin{tabular}{llll}
\hline BC & BC type & Fluid & Solid \\
\hline Inlet & Velocity inlet & $13.7 \mathrm{~m} / \mathrm{s}$ & $500 \mathrm{rpm}$ \\
Outlet & Pressure outlet & 0 & 0 \\
Interface & Wall & - & Moving wall \\
Surface & Wall & No slip & - \\
Wall & No slip & - & symmetry \\
\hline
\end{tabular}

By using above mentioned boundary conditions, velocity of water flowing through turbine and pressure drop across different parts was analyzed using software. As it can be seen from total pressure contour displayed below, total pressure is decreasing since the velocity water decreasing from inlet to nozzles pass guide vane.

\subsection{Simulation Set up and Analysis}

The viscous fluxes are computed with a "high-resolution" scheme, which means that in regions with low variable gradients, a second order upwind scheme is used. In areas where the gradients change sharply, a first-order upwind scheme is used to maintain robustness. Besides, root mean squared convergence criteria with an average residual target of $1 \times 10^{-4}$ in mass, momentum and turbulence $(\mathrm{k}-\varepsilon)$ equations is used.

It is known that total pressure is computed based on dynamic pressure and static pressure of water flow through turbine including the nozzle. Since the water is incompressible, density and temperature of water do not affect the magnitude of pressure. Pressure variation is mainly caused due to hydraulic head and flow of water through different configurations. Dynamics pressure is mainly depends up on the flow velocity. This circumstance can easily be seen from illustrated total pressure contours.

Static pressure of the water flow is computed based on static head of flow through penstock via nozzle. Since the fluid flow properties like density does not change with application of pressure, it is affected with hydraulic head. In general the flow is assumed to be isothermal. No temperature 
variation can influence the pressure of water inside penstock and turbine blades.

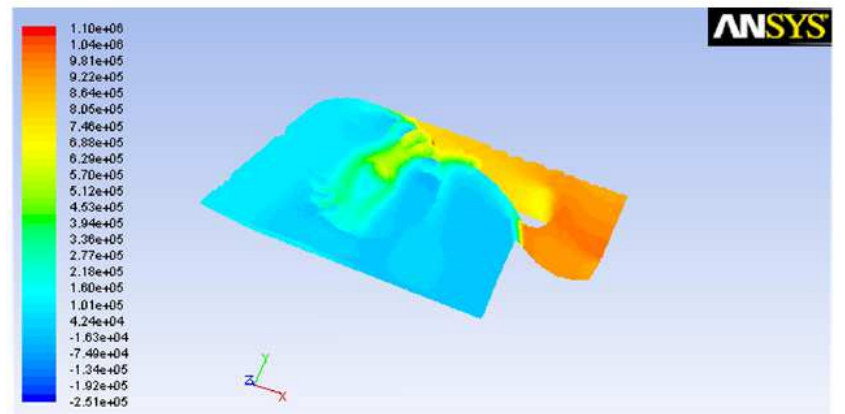

Contours of Total Pressure (pascal) ANSYS FLUENT 12.1 (3d, dp, pbns, ske)

Figure 2. Total pressure contours.

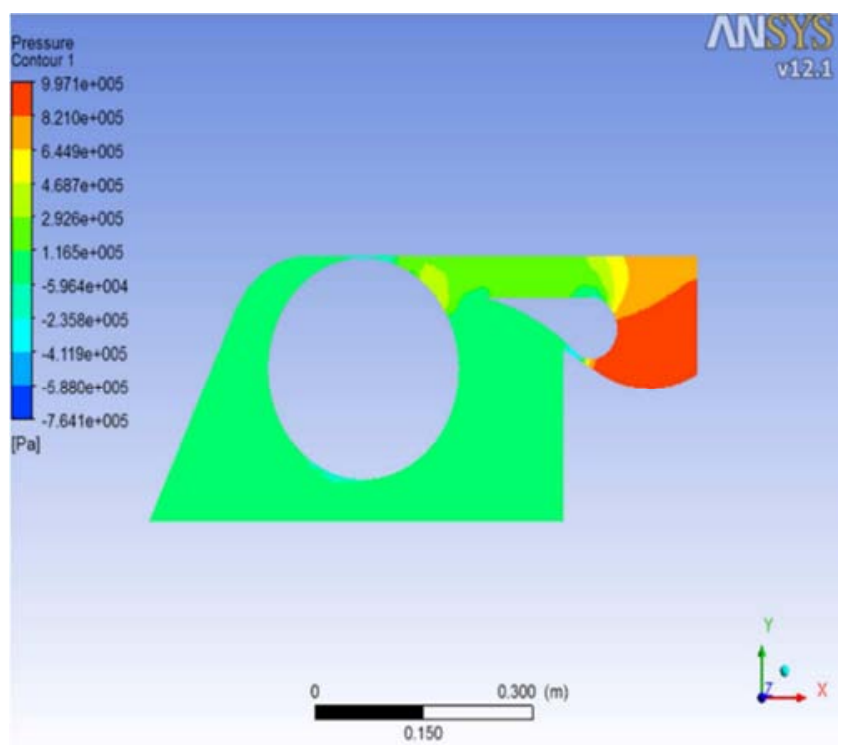

Figure 3. Static pressure contours.

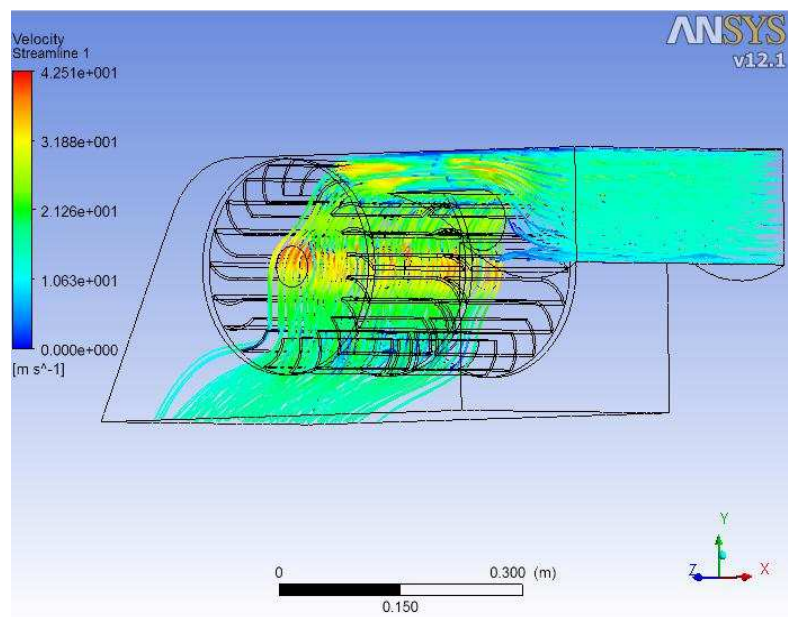

Figure 4. Velocity stream flow shown with front view.

Velocity of water in turbine nozzle is calculated to be $14.75 \mathrm{~m} / \mathrm{s}$ analytically. But this value was going to be validated with simulation. Magnitude of velocity is changed as cross-sectional area of pipe through which it flows fluctuated. Now velocity of flow through the turbine is computed on average based by taking maximum and minimum value.

The above velocity stream line illustrated that how the water strike the turbine blade which developed required torque. The torque developed enables the turbine to produce or generate power for various purposes. In such away the required work will be done.

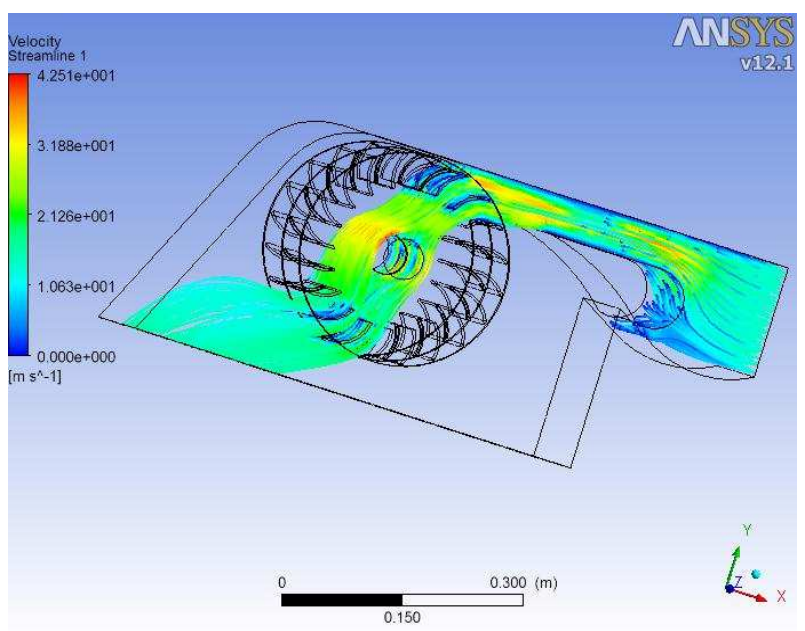

Figure 5. Velocity stream flow shown with right views.

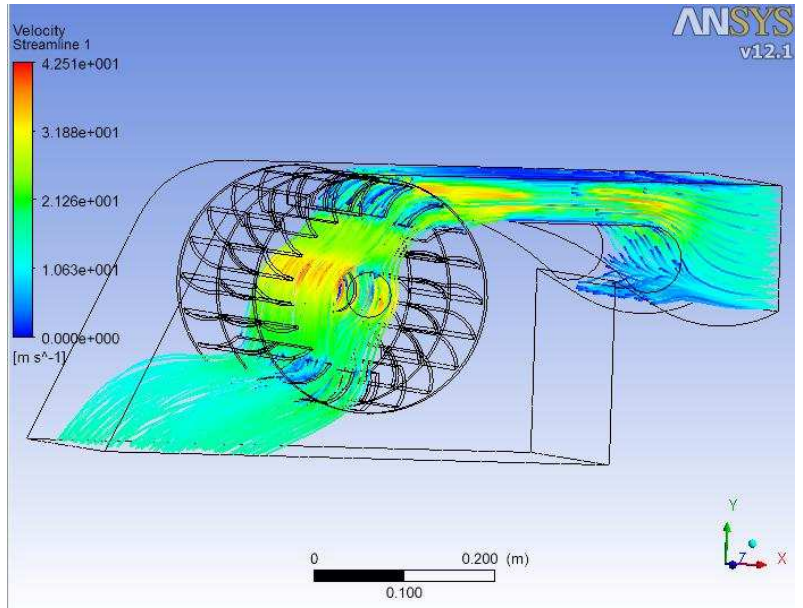

Figure 6. Velocity stream flow with various views.

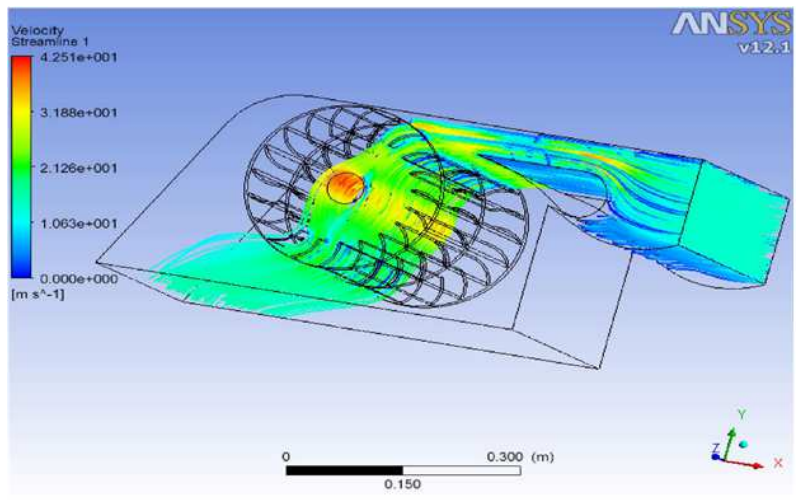

Figure 7. Velocity stream flow with various views. 
Velocity stream line shows that water flow passes through the turbine stages. As it is seen from streamline profile, the water flow through tangent to blade of the turbine in both first and second turbine stages. To make it clear and visualizes it easily, the flow pattern is shown with different views.

As the turbine gate open $90 \%$ and $80 \%$, strong jet of water going to be created in the turbine. This phenomena enables water to strike the turbine blade effectively and efficiently. In such away, important power can easily be generated in the power house with available water resources.

\section{Conclusion}

In case of low head and flow rate, cross-flow hydraulic turbine is suitable for small hydro power plants. Here in this particular paper, whole theoretical design and numerical simulation of the turbine has been prepared. In several literature, it was indicated that attack angle should be kept as small as possible for maximum efficiency [5, $15 \& 16]$. By considering this, attack angle of 18 degree was selected.

With this attack angle, maximum efficiency was found to be $82.52 \%$ constant for different values of head and water flow rate. Where as in CFD simulation case, maximum efficiency became $79 \%$ with fully opened guide vane. Guide vane was set at position where the water is discharge through the runner fully.

At this maximum turbine efficiency, complete turbine parameters such as runner diameter, runner length, water jet thickness, blade spacing and number of blades were determined.

\section{References}

[1] Bilal A. N., "Design of High Efficiency Cross-Flow Turbine for Hydro-Power Plant", International Journal of Engineering and Advanced Technology, ISSN: 2249 - 8958, Volume-2, Issue-3, 2013.

[2] Khosrowpahan, S., "Experimental Study of the Crossflow Turbine", Ph.D. Dissertation, Colorado State University, Fort Collins, CO, 1984.

[3] Nakase, Y., Fukutomi, J., Wantanabe, T., Suessugu, T., and Kubota, T., "A study of Crossflow Turbine", Small Hydro Power Fluid Machinery, p. 13-18, 1982.

[4] Akerkar, B. P., "A Study of the Performance of the Crossflow Turbine", M. S. Thesis, Clemson University, Clemson, SC, 1989.
[5] Fiuzat, A. A., and Akerkar B. P., "The Use of Interior Guide Tube in Crossflow Turbines", International Conference on Hydropower; Waterpower, pp. 1111-1119, 1989.

[6] Chappell, J. R., "Recent DOE-Sponsored Hydropower Engineering Research”, Report No. ECG- M-02983, p6, 1983.

[7] Simpson, B. J., "Low Head, Micro-Hydro Demonstration Project, Coker Alabama, Final Report”, Report No. DOE/R4 10233-TI, 1983.

[8] Hayati Olgun, "Effect of interior guide tubes in cross-flow turbine runner on turbine performance", International Journal of Energy Research, John Wiley \& Sons, p 953-964, 2000.

[9] Hayati Olgun, "Investigation of the Performance of a CrossFlow Turbine", International Journal of Energy Research, John Wiley \& Sons, pp 953-964, 1998.

[10] Durgin W. W and Fay W. K, "Some Fluid Flow Characteristics of a Cross-Flow Type Hydraulic Turbine" Small Hydro Power Fluid Machinery, 1984, p77-83. The Winter Annual meeting of ASME, New Orleans, L. A, December 9-14, 1984.

[11] Nadim M. Aziz and V. R. Desai, "An Experimental Study of the Effect of Some Design Parameters in Cross-Flow Turbine Efficiency", Engineering Report, Department of Civil Engineering, Clemson University, 1991.

[12] Thapar, O. D., and Albertson, M. L., "Ultra Low Head Small Hydro Power System Technology for Economic Development", Waterpower, 1985.

[13] H. Grotjans and F. R. Menter, "Wall functions for general application CFD codes" in Proceedings of the 4th European Computational Fluid Dynamics Conference (ECCOMAS '98), John Wiley \& Sons, Athens, Greece, pp. 1112-1117, September 1998.

[14] IORDANOU GRIGORIS, "Flat-Plate Solar Collectors foe Water Heating with Improved Heat Transfer for Application in climatic Conditions of the Mediterranean region", Doctor of Philosophy Dissertation, School of Engineering and Computing Science Durham University, 2009.

[15] Y. Choi, J. Lim, Y. Kim, and Y. Lee, "Performance and internal flow characteristics of a cross-flow hydro turbine by the shapes of nozzle and runner blade," Journal of Fluid Science and Technology, vol. 3, no. 3, pp. 398-409, 2008.

[16] F. Arzola, C. Rodriguez, J. Martin, J. De Andrade, A. V'asquez, and M. Asuaje, "Technical assessment for overhaul project in small hydro power plant," in Proceedings of the $24^{\text {th }}$ Symposium on Hydraulic Machinery and Systems (IAHR '08), Iguassu, Brazil, October 2008. 